\title{
A medicalização do "fracasso escolar" em escolas públicas municipais de ensino fundamental de Vitória-ES
}

\begin{abstract}
RESUMO: Este estudo apresenta uma análise do processo de medicalização da educação em escolas municipais de ensino fundamental de Vitória, Espírito Santo. Tem por principal objetivo conhecer os motivos de encaminhamento para diagnóstico médico de 1.628 alunos matriculados em 45 escolas públicas de ensino fundamental, no ano letivo de 2013. Com esse propósito, foi desenvolvido um estudo documental com abordagem quantiqualitativa. Foi utilizado para análise dos dados o software Statistical Package for the Social Sciences (SPSS), versão 20.0, mediante a estatística descritiva, com tabelas de frequência simples e gráficos com cruzamentos. Foram definidas oito categorias de análise que emergiram dos encaminhamentos realizados, entre as quais duas se destacaram: dificuldade de aprendizagem, perfazendo um total de $67 \%$ dos alunos encaminhados; e problema de comportamento, com $54,8 \%$. Os resultados obtidos demonstraram ainda que os alunos encaminhados eram, em sua maioria, do sexo masculino, totalizando $67,6 \%$. A faixa etária predominante se encontrava entre 8 e 10 anos, equivalendo a 41,3\% dos alunos encaminhados, seguida da faixa etária entre 11 e 13 anos, que foi $31,6 \%$. Essa faixa etária corresponde ao ensino fundamental I, tendo uma porcentagem equivalente a $72,3 \%$, com destaque para os matriculados no segundo e terceiro anos. Constatou-se, ainda, que, desde a idade de 13 anos, os encaminhamentos caem abruptamente. Quanto ao ano escolar, essa queda começa no quinto ano, sendo quase inexistente o número de encaminhamentos realizados no nono ano.
\end{abstract}

Palavras-chave: Medicalização. Educação. Escola Pública.

\section{Introdução}

Este artigo apresenta análise do processo de medicalização da educação, tendo por foco a rede municipal de ensino de VitóriaEspírito Santo (ES). Sendo medicalização um conceito polissêmico (OLIVEIRA; HARAYAMA; VIÉGAS, 2016), convém, desde já, explicitar o que entendemos pelo conceito, o que faremos apoiadas no Fórum sobre Medicalização da Educação e da Sociedade (2015a, p. 1):

medicalização envolve um tipo de racionalidade determinista que desconsidera a complexidade da vida humana, reduzindo-a a questões de cunho individual, seja em seu aspecto orgânico, seja em seu aspecto psíquico, seja em uma leitura restrita e naturalizada dos aspectos sociais. Nessa concepção, características comportamentais são tomadas apenas a partir da perspectiva do indivíduo isolado, que passaria a ser o único responsável por sua inadaptação às normas e padrões sociais
Elizabete Bassani

Universidade Federal do Espírito Santo (UFES)

betebassani23@gmail.com Lygia de Sousa Viégas Universidade Federal da Bahia (UFBA)

lyosviegas@gmail.com 
dominantes. A medicalização é terreno fértil para os fenômenos da patologização, da psiquiatrização, da psicologização e da criminalização das diferenças e da pobreza. ${ }^{1}$

Pensar o processo crescente de medicalização nas escolas públicas no Brasil implica em considerar a exclusão histórica de parte da população do direito à escolarização, sempre acompanhada de concepções individualizantes sobre o fracasso escolar. (PATTO, 1990)

Trata-se de escolas submetidas à "colonização médica" (ILLI$\mathrm{CH}, 1975)$, devido ao poder exercido pela medicina em nossa sociedade. Foucault (2001, p. 205) faz referência à psiquiatria e seus efeitos, a qual se funda como ciência dos anormais e das condutas anormais:

Não será mais simplesmente nessa figura excepcional do monstro que o distúrbio da natureza vai perturbar e questionar o logo da lei. Será em toda parte, o tempo todo, até nas condutas mais ínfimas, mais comuns, mais cotidianas, no objeto mais familiar da psiquiatria, que esta encarará algo que terá, de um lado, estatuto de irregularidade em relação a uma norma e que deverá ter, ao mesmo tempo, estatuto de disfunção patológica em relação ao normal.

A realidade de quase todo o país revela baixos índices nas avaliações externas da educação básica, demonstrando que a maior permanência de alunos nas escolas não implica aprendizagem; ao mesmo tempo, o aumento de alunos encaminhados para diagnóstico médico em várias regiões do Brasil indica a suposição de que o problema seria do indivíduo, principalmente de sua biologia.

Essa realidade levou-nos a realizar este estudo, que buscou conhecer os motivos de encaminhamento para diagnóstico médico de 1.628 alunos matriculados em 45 escolas públicas de ensino fundamental de Vitória-ES.

Apesar de suas especificidades, Vitória-ES não é um caso isolado de aumento da patologização da infância. Moysés (2011) denuncia que, em 2000, foram vendidas 70 mil caixas de um medicamento para tratar distúrbios de aprendizagem no Brasil e, em 2010, esse número chegou a dois milhões. O Brasil é o segundo maior consumidor de Cloridrato de Metilfenidato (nome comercial: Concerta e Ritalina) e seu consumo atingiu um crescimento de $775 \%$ entre 2003 e 2012 (BARROS, 2014). Segundo o Fórum sobre Medicalização da Educação e da Sociedade (2015b), o consumo dessa substância 
cresce a cada ano, sendo na Região Sudeste o maior número absoluto desse consumo. Os dados da cidade de Vitória são preocupantes, pois, se considerarmos a venda por Unidades Físicas Distribuídas (UFD) a cada mil habitantes, a capital capixaba fica em terceiro lugar no país, atrás somente de Porto Alegre e Goiânia. Esse ranking considerou dados de 2008 a 2013 que, em Vitória, variaram de 1,6 (2009) a 16,1(2012) UFD/1.000 habitantes.

Essa realidade tem uma história já descrita anteriormente, como em Patto (2007, 2009, 2015) e Moysés (2001). Todavia, insistimos em lembrar o contexto em que as diferenças de rendimento escolar entre crianças de diferentes origens sociais foram sendo constituídas e a maneira como explicações sobre essas diferenças buscaram, durante séculos, justificar o fracasso escolar de parte da população.Nesse artigo, não temos intenção de aprofundamento, até porque Patto (2015) nos dispensa dessa tarefa.

\section{A produção de ideias medicalizantes no contexto educacional: "fé cega, faca amolada"2}

No fim do século XVIII e início do século XIX, conforme descreve Patto (2015), a medicina passou a constituir seu estatuto de ciência moderna - período de grandes mudanças e revoluções no mundo ocidental -, quando a burguesia foi porta-voz do sonho de um mundo igualitário, fraterno e livre e, com isso, disseminou a crença de que esse sonho se concretizaria na sociedade industrial capitalista liberal. No entanto, conforme sabemos, esse sonho não se realizou; contraditoriamente, ocorreu o aprofundamento das desigualdades sociais e a segregação do trabalhador braçal.

A medicina será fundamental para legislar e normatizar, com suporte em suas concepções de saúde e doença, o que seria o "homem normal" e, assim, atribuir a todos os aspectos da vida humana determinantes biológicos e fisiológicos, servindo para explicar, com base em fundamentos orgânicos, as diferenças entre as pessoas e justificar as desigualdades sociais. Conforme discutiremos a seguir, tanto a medicina quanto as ciências humanas que nascem nesse período assumirão de forma dominante essa tarefa normativa.

Segundo Dardot e Laval (2016), a tarefa da psicologia foi contribuir para a economia política quando descreveu uma economia psíquica que a sustenta. Estereótipos e preconceitos raciais há séculos constituídos passam a adquirir um status de ciência ${ }^{3}$. 
(3) A respeito de uma discussão teórica acerca do conceito de preconceito, sugerimos a leitura de Crochík (1995)
De acordo com Patto (2015), a fisiologia inicia estudos que procuram explicar as diferenças individuais e raciais e, em conjunto com a sociologia, antropologia e psicologia, contribuirá para legitimar a sociedade de classes e a desigualdade social. Contudo, a psicologia certamente ocupou posição de destaque nessa função entre as ciências humanas, já que desenvolveu teorias com o propósito de explicar as diferenças individuais e seus determinantes, com a detecção científica dos normais e anormais, dos aptos e inaptos. E os supostos inaptos eram principalmente os estudantes e trabalhadores pobres.

Com fundamentos em Galton e em sua teoria sobre a inteligência herdada, psicólogos e pedagogos, na virada do século XIX, desenvolveram uma psicometria e uma pedagogia "a serviço de uma sociedade (de classes) igualitária”. (PATTO, 2015, p. 64)

Ante o desenvolvimento da psicometria e mais especificamente dos resultados dos testes de inteligência, a psicologia passou a contribuir com a ideia de que os mais aptos ocupavam os melhores lugares sociais e, assim, com critérios "justos" e "neutros", poderia colocar "o homem certo no lugar certo". Nesse contexto, os testes psicológicos passaram a compor o cotidiano escolar. Apesar disso, a psicologia não foi pioneira nas explicações científicas sobre as dificuldades de aprendizagem, papel desempenhado pela medicina. As crianças que não conseguiam acompanhar o ritmo escolar passaram a ser consideradas anormais e as causas eram relacionadas a aspectos orgânicos. O darwinismo social também vai sustentar a biologização de fenômenos sociais, constituindo terreno fértil onde se fundaram as teorias que tentaram justificar a discriminação entre os homens.

Nas primeiras décadas do século XX, as crianças que não atendiam às exigências escolares passaram a ser submetidas a diagnósticos médico-psicológicos. E quem mais fazia parte desse contingente eram, mais uma vez, os alunos das classes pobres. Segundo Patto (2015), nessa época, o peso atribuído à hereditariedade e à raça na determinação do comportamento já havia diminuído. Diante da recorrência de dados que apontavam negros e trabalhadores pobres como detentores de resultados mais baixos nos testes psicológicos, a explicação começava a deixar de ser apenas racial para ser cultural, indicando que, apesar da mudança no discurso, mantém-se os preconceitos. 
Essa tendência atingiu seu ponto mais alto nos anos 1960, mediante a elaboração da chamada "teoria da carência cultural", a qual se fundamentava em preconceitos e estereótipos que, com nova fachada científica, passavam a orientar a política educacional. Esses fundamentos sustentaram entre educadores suas antigas visões preconceituosas das crianças pobres e suas famílias, anulando a análise do contexto social num processo de despolitização que reforça a medicalização. Tal olhar ainda hoje permanece, fundamentando, em 2013, o Manual de Diagnóstico e Estatística de Doenças Mentais (DSM-5).

Considerando que a história é feita de continuidades e rupturas, chegamos ao século XXI com o fortalecimento de concepções que naturalizam a tendência de tratar crianças e adolescentes com medicamentos psiquiátricos. Tais concepções, segundo Whitaker (2016), são apresentadas pela psiquiatria americana como uma história de avanço médico, visto que agora os transtornos psiquiátricos são considerados doenças do cérebro, determinadas por alterações químicas que precisam ser "corrigidas".

Atualmente muitas crianças recebem diagnóstico (Transtorno de Déficit de Atenção/Hiperatividade - TDAH, Transtorno de Oposição Desafiante - TOD, depressão, transtorno bipolar...), e muitos médicos prescrevem, segundo Whitaker (2016), como primeira opção de tratamento, medicamentos psiquiátricos. Leitura crítica desse cenário parece descrever um mundo ficcional.

Essa narrativa defende que estaríamos diante de um avanço no diagnóstico e tratamento de doenças e isso seria benéfico para as crianças. Porém, conforme demonstra uma revisão da história e da ciência, essa prática "é mais bem compreendida como uma empresa de negócios, que causa danos consideráveis quando estudados seus resultados a longo prazo". (WHITAKER, 2016, p. 13)

Essa concepção, para além de seu caráter ideológico, passa a atender aos interesses da indústria farmacêutica, que tem um aumento crescente em seus lucros com a medicalização da infância. Segundo Whitaker (2016), nos Estados Unidos, mais de 7\% das crianças entre 6 e 17 anos utilizam pelo menos um medicamento psiquiátrico diário, evidenciando que a indústria farmacêutica, em colaboração com a Associação Americana de Psiquiatria (APA), construiu um novo mercado consumidor. Essa prática foi exportada dos Estados Unidos para grande parte do mundo, e, como não poderia ser diferente, para o Brasil. O autor ainda denuncia que, 
(4) Para discussão aprofundada sobre o neoliberalismo e seus impactos objetivos e subjetivos na sociedade brasileira, sugerimos a leitura de Dardot e Laval (2016).

entre 1987 e 2007, o número de crianças incapacitadas por doenças mentais aumentou 35 vezes nos Estados Unidos, tornando-se a principal causa de invalidez nas crianças. O grupo de doentes mentais abrangeu $50 \%$ do total de crianças no rol da renda complementar da previdência americana em 2007.

A crescente tendência de tratar crianças com medicamentos psiquiátricos, banalizada em tempos neoliberais, ${ }^{4}$ está associada aos fundamentos do DSM-5. Segundo Caponi (2016, p. 30):

\begin{abstract}
Gostaria de me deter aqui a analisar de que modo a nova versão do Manual se vincula com esse dispositivo de saber-poder próprio das sociedades liberais e neoliberais, denominado por Michel Foucault 'dispositivo de segurança' (FOUCAULT, 1978, 1997, 2004, 2005): um dispositivo eminentemente centrado na lógica da prevenção e da antecipação de riscos. Certamente esse dispositivo não aparece por primeira vez em 2013, porém ele foi ganhando força graças à consolidação de uma linha de pesquisa, cada vez mais consolidada no campo da psiquiatria, denominada 'psiquiatria do desenvolvimento da infância e da adolescência'.
\end{abstract}

Nesse sentido, os diagnósticos precoces ganham legitimidade na medida em que supostamente cumpririam a função de prevenção e, consequentemente, de proteção social, uma vez que os comportamentos patológicos seriam uma ameaça à ordem social. A partir de um ideário segundo o qual os transtornos podem agravar-se no transcorrer da infância à vida adulta, sustenta-se a lógica de que é necessária atenção preventiva nos primeiros anos de vida. Com isso, comportamentos próprios da infância passaram a ser vistos como indício de problemas. Assim, crianças apenas sendo crianças, ou respondendo a um mundo hostil, correm risco de ganhar um diagnóstico, melhor dizendo, rótulo. Whitaker (2017, p. 28) retrata uma triste realidade: "nossas crianças são as primeiras da história humana a crescerem sob a sombra constante da 'doença mental'".

Ainda, segundo Whitaker, não é preciso retroceder muito na história para lembrarmos que crianças tímidas, agitadas, arteiras ou caladas eram consideradas normais. Ninguém sabia seus destinos, já que, devido à complexidade humana,a incerteza sempre fez parte da vida.

Hoje em dia, no entanto, as crianças diagnosticadas com problemas mentais - em especial transtorno de déficit de 
atenção com hiperatividade [TDAH], depressão e transtorno bipolar - ajudam a povoar o pátio estudantil. Essas crianças são informadas de que há algo errado com seu cérebro e de que talvez tenham que tomar remédios psiquiátricos pelo resto da vida, assim como 'o diabético toma insulina'. Essa máxima da medicina ensina a todos do pátio uma lição sobre a natureza da humanidade, e essa lição difere radicalmente do que se costumava ensinar às crianças. (WHITAKER, 2017, p. 28)

Segundo Caponi (2016), apesar de o DSM-5 estabelecer causas biológicas para diagnósticos psiquiátricos, contraditoriamente utiliza outros fatores de risco e de prognóstico denominados ambientais, o que demonstra como os preconceitos contra os pobres sustentam essas concepções. Entre os fatores de risco, a APA (2014) incluiu como causa dos transtornos a negligência na criação dos filhos. Com isso, crianças pobres acabam novamente sendo mais diagnosticadas na medida em que a necessidade de trabalhar que atravessa a vida familiar as coloca em situação de maior vulnerabilidade. Ante esse paradigma fisicalista, perguntamos: a quem serve a disseminação desta "verdade"? Quais seriam seus reais desdobramentos na vida de crianças, sobretudo as mais pobres?

A narrativa vigente na atualidade reforça que a psiquiatria se desenvolveu e hoje conta com novos conhecimentos sobre a química cerebral e com novos exames de neuroimagem extremamente eficientes. Apesar da importância desses exames para a detecção de diversas doenças, é notável que eles podem tornar-se instrumento de disseminação de "preconceitos de classe apresentados sob a forma de estudos científicos". (CAPONI, 2016, p. 39)

Caponi (2016) ainda questiona: como um manual que afirma ser sustentado por preceitos científicos se defende que os transtornos mentais têm origem na alteração da química cerebral e busca critérios para a definição desses transtornos com base na escolaridade da mãe ou negligência familiar? Ou numa lista de comportamentos que provocam incômodo em quem convive com as crianças? Tais questionamentos denunciam que comportamentos definidos no DSM-5 como patológicos podem ser a única forma de crianças demonstrarem sofrimento em um cotidiano preconceituoso e opressor, como o de muitas escolas brasileiras. Não é porque indivíduos sofrem que a causa seja biológica. Crianças podem sofrer por causas externas a elas, a seus corpos: causas sociais, políticas, econômicas. E até mesmo podem não estar sofrendo, apenas sendo crianças incomodando adultos que falam por elas. 
À luz de Caponi (2016), refletimos que esse discurso passa a dominar as narrativas de educadores no contexto escolar, quando preconceitos, disfarçados de preocupação e cuidado, passam a fundamentar encaminhamentos médicos. Os profissionais que encaminham alunos, assim como os que diagnosticam com "supostos transtornos", parecem ter concepções que sustentam a ideia de uma infância única e modelar, e desconsideram que o cotidiano insiste em apresentar inúmeras infâncias. As que fogem do modelo devem ser normalizadas, pois, segundo Dardot e Laval (2016), poriam em risco o projeto neoliberal, em que só há lugar para o humano da competição e do desempenho ilimitado. O empreendedor de si, um ser feito para "ganhar", ser "bem-sucedido", um deus do desempenho, prematuramente avaliado.

[...] com quinze anos, somos empreendedores de nós mesmos assim que nos perguntamos o que queremos fazer da vida. Toda atividade é empresarial, porque nada mais é garantido para toda a vida. Tudo deve ser conquistado e defendido a todo momento. A criança mesmo deve ser 'empreendedora de seu saber' $[. .$.$] .$ (DARDOT; LAVAL, 2016, p. 336)

À vista disso, quanto mais cedo percebemos que a criança está saindo desse projeto (que envolve a constituição de um sujeito que tem no foco melhorar desempenho e produzir sempre mais), tanto mais ela precisa ser corrigida (por ter perdido o foco ou estar se opondo a ele). E, nessa lógica, onde a escola deixa de ser uma instituição e passa a ser uma empresa, com metas a atingir, com seus muros altos, grades nos portões, "grades curriculares", ela não sabe lidar com aquele que, com seus comportamentos, problematiza a ordem instituída.

Por isso, insistimos na necessidade de pensar em infâncias, na contramão das concepções vigentes em nossa sociedade que, ao apostarem em uma única possibilidade, sustentam o processo de medicalização. Crianças gritam, correm, pulam, brincam, e isso nos diz que, em seus corpos, não há lugar para aprisionamentos, para aumento do desempenho e da produtividade, que começam cada vez mais cedo, na educação infantil. Elas denunciam que precisamos fundar novos modos de vida.

Dardot e Laval (2016, p. 367) analisam que o medicamento faz as vezes da instituição que não apoia, não reconhece, não protege os indivíduos isolados. "Vícios diversos e dependência às 
mídias visuais são alguns desses estados artificiais. O consumo de mercadorias também faria parte dessa medicação social, como suplemento de instituições debilitadas". E, nos contextos capixaba e brasileiro, há ainda o aumento do fundamentalismo religioso e militar, também com a função medicalizante, o que nos faz antever um futuro sombrio.

À luz dessa discussão, interessa-nos conhecer como essas concepções estão presentes no cotidiano escolar. Sendo assim, a seguir descreveremos a pesquisa realizada em 2017 e 2018, durante nosso estágio pós-doutoral, que retrata o encaminhamento para o diagnóstico médico de 1.628 alunos de ensino fundamental de escolas públicas de Vitória-ES, no qual buscamos responder às seguintes questões: Quem são os alunos encaminhados? Quais os motivos mais frequentes que levaram seus professores a encaminhá-los para diagnósticos médicos? A quem servem esses encaminhamentos?

\section{Trajetória metodológica}

A seguir descreveremos o caminho percorrido no processo de delimitação do objeto de estudo, assim como no desenvolvimento da pesquisa e análise dos dados.

Caracterização e local do estudo

O interesse no presente estudo surgiu em 2013, quando, em reunião com pedagogas da Coordenação de Formação e Acompanhamento à Educação Especial da Secretaria Municipal de Educação de Vitória, soubemos que, devido à grande demanda de encaminhamento médico de alunos por parte das escolas de ensino fundamental, tal equipe elaborou uma Circular, por meio da qual solicitava que todas as escolas enviassem a relação de alunos que apresentassem demanda de diagnóstico e intervenção médica, a descrição dos motivos de encaminhamento, além de informações de identificação (idade, sexo, ano e turno de matrícula e escola). A lista completa seria encaminhada ao Ministério Público, para que todos os alunos tivessem direito a uma avaliação diagnóstica e, se necessário, posterior tratamento. Isso sem considerar os alunos que já haviam sido diagnosticados e faziam parte da educação especial.

Do total de 53 escolas da rede, 45 responderam à solicitação da Secretaria Municipal de Educação de Vitória (SEME), gerando uma produção de 1.628 encaminhamentos em 2013. Em 2014, 
a SEME disponibilizou para a pesquisa a cópia de todos os encaminhamentos, tornando possível a análise de tais dados, com abordagem quantiqualitativa.

Vitória, segundo dados do Instituto Brasileiro de Geografia e Estatística (IBGE, 2010), contava, à época, com população estimada em 327.801 habitantes, dos quais 153.948 homens (46,96\%) e 173.853 mulheres (53,04\%). No mesmo ano, segundo dados da SEME, o número de alunos matriculados nas 53 escolas municipais de ensino fundamental, localizadas nas oito regiões administrativas do município, era de 27.906 alunos. Deste total, 50,36\% estudavam no turno matutino e 49,64\% no vespertino, sendo 54,04\% nas séries iniciais e 45,95\% nas séries finais. Destes, 51,41\% do sexo masculino e 48,59\% feminino.

Considerando que as 45 escolas totalizaram 24.512 matrículas no ensino fundamental no ano da pesquisa, o número de alunos encaminhados equivale a 6,65\%. Tal documento não trazia informações sobre dados étnico-raciais; entretanto, segundo dados da SEME, 70\% dos alunos das escolas participantes autodeclararam-se pretos ou pardos no contexto da matrícula.

\section{Coleta de dados}

De posse dos documentos, inicialmente foi realizada a primeira leitura de todos os 1.628 encaminhamentos, quando notamos que as escolas enviaram formulários diferentes. Diante disso, realizamos a releitura exaustiva do material, até chegar a uma síntese do seu conteúdo, buscando identificar, nas informações disponíveis, recorrências e singularidades. A partir disso, emergiram oito categorias referentes aos motivos dos encaminhamentos, assim nomeadas: 1. Problemas familiares; 2. Dificuldade de aprendizagem; 3. Problema comportamental; 4. Diagnóstico "fechado"; 5. Problemas de saúde relacionados à medicina geral; 6. Problemas de linguagem/fala; 7 . Problemas psicológicos/psiquiátricos; 8. Outros motivos.

O passo seguinte consistiu em inserir os dados dos 1.628 encaminhamentos em uma planilha Excel, para, então, por meio do software Statistical Package for the Social Sciences (SPSS), versão 20.0, produzir a estatística descritiva, com tabelas de frequência simples e gráficos com cruzamentos, bem como analisar criticamente os dados encontrados, o que apresentamos a seguir. Por se tratar de censo, abrangendo 45 do total de 53 escolas, não há margem de erro a ser considerada. 


\section{Conhecendo os alunos encaminhados}

A seguir descreveremos os dados obtidos referentes aos 1.628 alunos encaminhados.

\section{A predominância do sexo masculino: um sistema escolar domesticador}

Os alunos encaminhados são, em sua maioria, do sexo masculino, totalizando 67,6\%. Essa porcentagem é muito semelhante à encontrada em outros estudos, como os de Carvalho (2004), Souza (2000), Souza e Sobral (2007), Vitorino (2009), que demonstram um crescente aumento da diferença no desempenho escolar de meninos e meninas nos últimos anos, no cotidiano das escolas brasileiras.

Há algumas décadas, as estatísticas não demonstravam essa realidade porque o acesso às escolas públicas brasileiras era privilégio de poucos e as mulheres eram mais excluídas. Entretanto, na atualidade, temos mais de 90\% das crianças brasileiras em idade escolar matriculadas no ensino fundamental (dado assustador, pois desvela que o ensino não foi universalizado em pleno fim da segunda década dos anos 2000). Nesse novo cenário, ocorreu uma inversão, pois, de acordo com Carvalho (2004), em 1999, as mulheres apresentavam, em média, 5,9 anos de estudo e os homens 5,6 anos.

[...] considerando o recorte por sexo, nas faixas etárias acima de 45 anos vamos encontrar mais mulheres do que homens analfabetos, enquanto na faixa de 15 a 19 anos temos quase o dobro da proporção de rapazes (5,3\%) que moças analfabetas $(2,7 \%)$. [...] e esse é um indicador de que a escola está fracassando frente a um grupo grande de jovens no qual se concentra uma maioria de pessoas do sexo masculino. (CARVALHO, 2004, p. 249)

Foram frequentes encaminhamentos como este: Aluno do 4. ${ }^{\circ}$ ano, com 9 anos, sexo masculino, tendo por motivos "Comportamento infantil, corre, brinca em momentos inadequados, não presta atenção, agitado. Não respeita regras e normas. Não consegue aprender a ler e escrever".

O fato é que um maior número de meninos tem sido conduzido para avaliação médica, indicando que seus professores consideram que eles possuem problemas individuais que os impedem de aprender na escola. Tais encaminhamentos, muitas vezes, estão 
atravessados por valores e preconceitos relativos às relações de gênero que ganham corpo no chão da escola.

Essa diferença de gênero relaciona-se a estereótipos de uma sociedade machista. Do sexo masculino espera-se a agressividade, a iniciativa, a liderança. Do feminino, a doçura, a passividade, a submissão. Em um sistema escolar domesticador, as meninas tornam-se, assim, mais adequadas e podem passar pelo mesmo com maior facilidade e sucesso. O que não ocorre com os meninos, cujo papel social entra em conflito com o que a escola espera deles. (SOUZA; SOBRAL, 2007, p. 121)

O olhar pejorativo da escola para os meninos reflete o lugar social a eles destinado no contexto brasileiro, onde comumente são percebidos como anormais, ou mesmo marginais em potencial, razão pela qual precisam ser corrigidos. Provavelmente parte deles comporá as estatísticas da violência em um curto período de tempo. Segundo analisa o Atlas da Violência (INSTITUTO DE PESQUISA ECONÔMICA APLICADA E FÓRUM BRASILEIRO DE SEGURANÇA PÚBLICA, 2018, p. 32):

A vitimização por homicídio de jovens (15 a 29 anos) no país é fenômeno denunciado ao longo das últimas décadas, mas que permanece sem a devida resposta em termos de políticas públicas que efetivamente venham a enfrentar o problema. Os dados de 2016 indicam o agravamento do quadro em boa parte do país: os jovens, sobretudo os homens, seguem prematuramente perdendo as suas vidas. No país, 33.590 jovens foram assassinados em 2016, sendo 94,6\% do sexo masculino. Esse número representa um aumento de 7,4\% em relação ao ano anterior. Se, em 2015, pequena redução fora registrada em relação a 2014 (-3,6\%), em 2016 voltamos a ter crescimento do número de jovens mortos violentamente.

Mesmo que há décadas pesquisas demonstrem essa realidade, essa discussão não tem recebido a importância necessária. Assim, concluímos pela necessidade de aprofundar o estudo sobre os preconceitos que fundamentam práticas escolares direcionadas aos meninos, principalmente pobres e negros, que se hoje ocupam o lugar da exclusão nos bancos escolares; são o perfil daqueles que, em breve, podem ser exterminados. 


\section{A idade e o ano escolar como sintoma}

Os dados obtidos também desvelam que a faixa etária predominante se encontra entre 8 e 10 anos, equivalendo a 41,3\% dos alunos encaminhados, seguida da faixa etária entre 11 e 13 anos, que foi 31,6\%, conforme podemos observar no gráfico abaixo.

\section{GRÁFICO 1 - Percentual de alunos encaminhados por faixa etária}

Tais dados indicam a tendência das escolas a encaminhar as crianças menores, ainda em início de escolarização, corroborando com outras pesquisas, como Souza e Sobral (2007). Segundo Whitaker (2016, p. 18), essa realidade também é vista no Canadá, onde "as

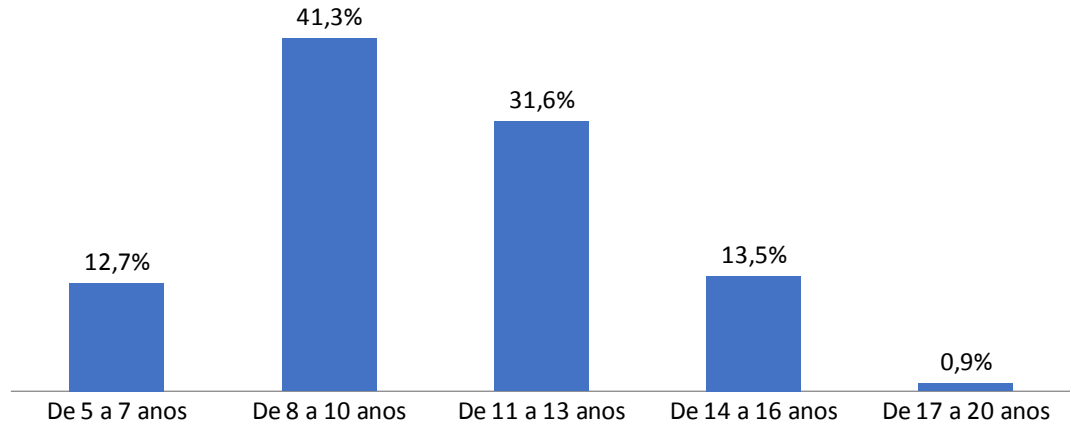

Fonte: Dados da pesquisa (2018).

crianças mais novas têm 30\% mais chance de serem diagnosticadas com TDAH do que crianças mais velhas".

Ser criança pode ser um problema na escola, o que fica evidente em vários encaminhamentos encontrados e ilustrados no exemplo a seguir: Aluno do $4^{\circ}$ ano, 9 anos, sexo masculino, com os seguintes motivos: "Fica aéreo. Brinca com canetas e lápis. Comportamento infantil. Dificuldade de compreensão".

$\mathrm{Na}$ atualidade, o brincar perde o sentido, pois a máxima é, como já discutido anteriormente (DARDOT; LAVAL, 2016), ser empreendedor, e todos, desde a infância, precisam incansavelmente buscar superar metas, aumentar desempenho e ser produtivos.

A faixa etária predominante dos alunos encaminhados corresponde aos cinco primeiros anos do ensino fundamental, ou seja, do primeiro ao quinto ano, equivalendo a 72,3\%, com destaque para o segundo e o terceiro anos. Segundo Souza e Sobral (2007, p. 129), esses são os momentos da escolarização em "que mais famílias, crianças e educadores têm esperança e motivação para lutar contra o fracasso escolar". Desse modo, haveria mais investimento 
por parte dos educadores e o encaminhamento dos alunos poderia indicar uma busca de solução dos problemas que enfrentam.

Tão preocupante quanto a epidemia de encaminhamentos entre alunos do ensino fundamental 1 é a constatação de que, a partir dos 13 anos de idade, os encaminhamentos caem abruptamente. Em relação ao ano escolar, essa queda começa no quinto ano, sendo quase inexistentes encaminhamentos de alunos do nono ano, conforme o gráfico a seguir:

\section{GRÁFICO 2 - Percentual de alunos encaminhados por ano escolar}

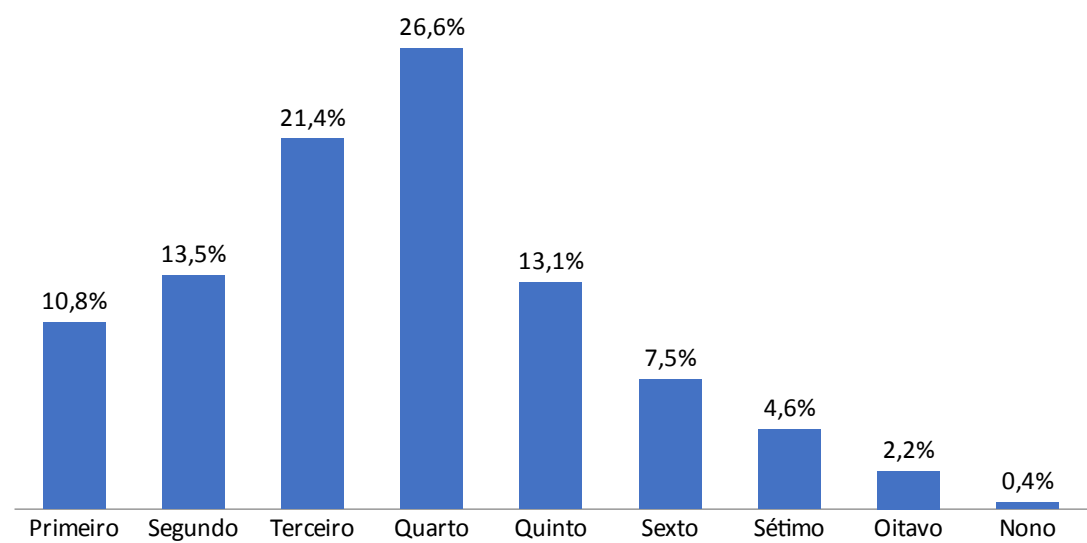

Fonte: Dados da pesquisa (2018).

Consideramos que o alto índice de encaminhamento realizado no final do ensino fundamental I pode ser analisado como pedido de socorro dos professores, que também sofrem por estarem sozinhos e não conseguirem compreender os alunos a quem precisam ensinar. Encaminhar alunos para outro profissional pode também decorrer da suposição de que precisam da ajuda de alguém que thes diga o que fazer e como ensinar.

No que diz respeito à queda nos encaminhamentos a partir do quinto ano, pode estar associada à realidade do cotidiano escolar. É nesse momento da escolarização que alunos passam a ter maior número de disciplinas, consequentemente um grande número de professores que, muitas vezes, trabalham em mais de uma escola e não conseguem sequer saber os nomes de seus alunos nem muito menos identificar suas dificuldades.

A diminuição dos encaminhamentos a partir dos 13 anos também pode refletir que, entre os professores, há uma desistência de investimento nesses alunos. Essa hipótese foi apresentada em estudo 
realizado por Bassani (2013), o qual demonstra que muitos alunos pobres, de bairros periféricos, ocupam hoje o lugar que denominou "inclassificável". Os professores, em sua grande maioria, não avaliam nem classificam esses alunos, não os reprovam, nem muito menos os encaminham a profissionais de saúde para diagnósticos de problemas de aprendizagem. São apenas indiferentes a eles.

Em seu estudo de caso etnográfico, Bassani (2013) descreveu o cotidiano de um aluno do nono ano do ensino fundamental que apresentava as piores notas em sua turma, além de ter sido reprovado duas vezes no sexto ano. Durante um ano e meio na escola pesquisada, a autora afirma não ter encontrado a lógica da medicalização da educação como tônica das práticas educacionais vigentes. Nas representações de muitos professores, seus alunos nem mereciam estar na escola. Uma nova categoria, a do aluno "inclassificável", "um aluno sem valor", aparece no cotidiano da escola estudada. Tão sem valor que não merece ser ensinado, nem avaliado, nem mesmo classificado; deve apenas seguir o fluxo, sem dar muito trabalho, tornar-se, ao final do ano letivo, uma média, quando, assim, desaparecerá nas estatísticas, sem direito sequer a um diagnóstico que justifique seu fracasso escolar, "inclassificável". Essa afirmação não tem como objetivo defender os diagnósticos, mas apenas destacar que até dessa lógica perversa esse aluno foi excluído. A novidade da proposta seria anular radicalmente todo estatuto jurídico do indivíduo, produzindo um ser inominável e inclassificável.

O lugar dado pela escola a eles demonstra um processo gradativo de construção de seu desaparecimento social, sendo a escola apenas um estágio para seu desfecho final. A morte simbólica na escola é um estágio para a morte biológica destinada a um grande número de meninos pertencentes a esse grupo social: abandonados. É possível que esta pesquisa, ao revelar que, no nono ano, o encaminhamento é quase inexistente, representado por $0,4 \%$, esteja desvelando essa mesma realidade, agora em maior escala.

\section{os motivos de encaminhamento}

Por último, apresentamos os percentuais referentes às categorias de motivos de encaminhamento, os quais são compreendidos, em sua totalidade, como problemas de escolarização. (SOUZA, 2007) 
Os dois motivos de encaminhamento que mais se destacaram foram "dificuldade de aprendizagem", perfazendo um total de $67 \%$ dos alunos; e "problema de comportamento", com 54,8\% dos encaminhados.

A seguir, apresentaremos um gráfico com as oito categorias de encaminhamento. É importante ressaltar que 54,5\% dos alunos foram encaminhados devido a duas ou mais categorias de motivos; por isso, a soma excede cem por cento.

\section{GRÁFICO 3 - Percentual de alunos encaminhados por motivo}

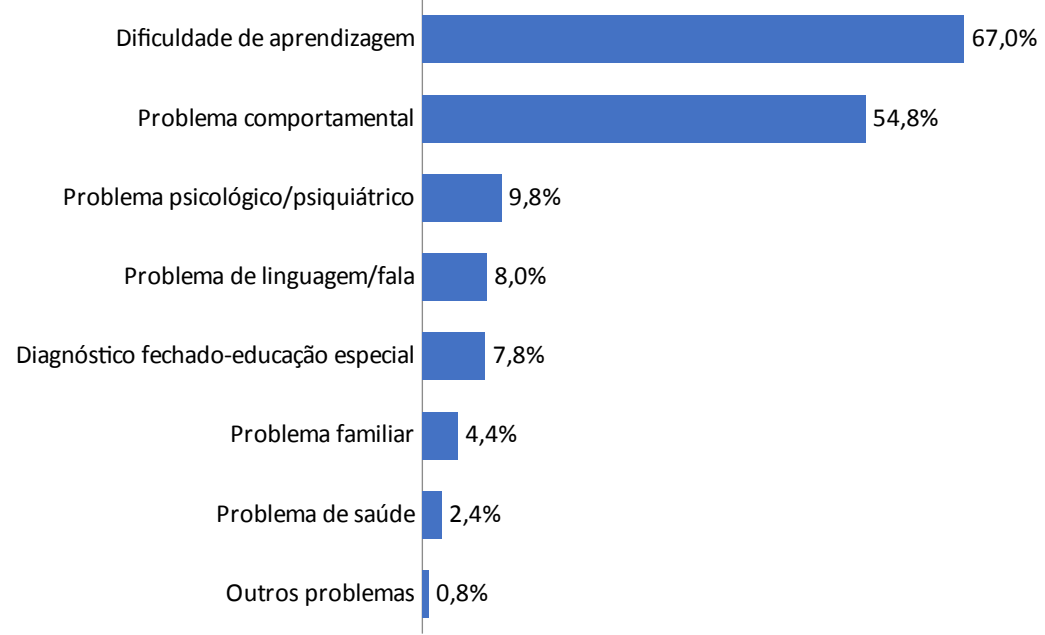

Fonte: Dados da pesquisa (2018).

De maneira geral, todas as categorias de respostas sugerem que os problemas estão fora da escola e que a dificuldade é do aluno. Mais uma vez, as causas do fracasso escolar centram-se nas crianças e nas famílias. A instituição escolar é isenta de responsabilidades. Isso pode ser notado quando analisamos a categoria "problema de aprendizagem", conforme encontrada nos registros dos documentos analisados, que foi dividida em três grupos:

a. Dificuldades referentes à aprendizagem da língua portuguesa: dificuldade de leitura e de escrita, caligrafia de difícil compreensão, dificuldade de alfabetização, troca letras, dificuldade para copiar do quadro e dificuldade de interpretação de texto;

b. Dificuldades na aprendizagem lógico-matemática: dificuldade para aprender números e as operações matemáticas; 
c. Dificuldades para memorizar: dificuldade para reter e assimilar o conteúdo, esquece os conteúdos e pouca memória.

Os dados apresentados mediante o cruzamento entre os motivos de encaminhamento e os anos escolares de matrícula reforçam que esses motivos aparecem predominantemente entre alunos dos cinco primeiros anos do ensino fundamental, totalizando 85,9\%.

No que concerne aos problemas comportamentais, que também foram predominantes entre alunos do Ensino Fundamental I, perfazendo $84,8 \%$, eles foram assim registrados:

a. Comportamento violento/agressivo: agressivo quando contrariado, grita na sala em momentos inadequados, quebra e rasga o material escolar;

b. Dificuldade para acatar normas e regras: desafia e ignora a maioria das solicitações, comportamento desafiador, não respeita autoridade, problema de indisciplina, é rebelde, resistência na adaptação curricular, reclama muito, só permanece em locais onde gosta de estar;

c. Comportamento instável/impulsivo: comportamento instável, instabilidade emocional, descontrolado, mudança de humor, atitudes intempestivas, não controla seus desejos, explode inesperadamente;

d. Dificuldade de relacionamento/socialização:dificuldade de relacionamento, provoca e atrapalha os colegas, desrespeita colegas e professores, não desenvolve hábitos e atitudes sociais, não tem amigos na escola;

e. Comportamento infantil: comportamento infantil, imaturo, fala e age de forma infantilizada;

f. Hiperativo/desatento: agitado, hiperativo, inquieto, anda pela sala, dificuldade para se manter sentado, foge da sala, apressado, desatento, sem concentração, desligado da realidade, aéreo, alheio, parece não ouvir e esquece seus objetos.

Segundo Moysés (2001), nos séculos XIX e XX, a medicina se apropriava da aprendizagem e, consequentemente, do não aprender como seu objeto de estudo. Doenças referentes à aprendizagem e ao comportamento passavam a fazer parte do saber médico, devendo ser tratadas. Esse saber deverá ser disseminado no ambiente escolar, para garantir que a aprendizagem seja possível a partir da intervenção médica. Nossa pesquisa desvela essa ampla disseminação nas escolas municipais de Vitória, pois educadores passaram a 
ter o poder de encaminhar, de modo sistemático, crianças, em sua maioria pobres e negras, para avaliação médica. No ano de 2013, 1.628 alunos foram encaminhados, mediante solicitação da Secretaria Municipal de Educação de Vitória. Tais encaminhamentos denunciam a presença de preconceitos produzidos historicamente no contexto escolar, sustentando concepções de aprendizagem e de comportamento que acabam por fundamentar políticas e práticas pedagógicas.

\section{Considerações finais}

A partir da pesquisa, é possível tecer considerações sobre o olhar voltado para as dificuldades de escolarização na rede municipal de Vitória-ES. Tomando de forma naturalizada o grande número de encaminhamentos espontâneos de alunos para diagnóstico médico por parte das escolas, a SEME solicitou a toda rede os alunos a serem encaminhados, o que desencadeou a produção de uma lista com 1.628 estudantes.

Esse processo parece se sustentar na colonização médica (ILLI$\mathrm{CH}, 1975)$, que legitima a ideia de que existem alunos incapazes de aprender, que devem ser submetidos à intervenção médica. Mas, no campo da educação, a intervenção não deveria ser de ordem pedagógica? Não deveríamos estranhar a invasão do discurso e olhar médicos nas escolas?

O Ensino Fundamental brasileiro, segundo dados do Sistema de Avaliação da Educação Básica, tem um dos piores desempenhos do mundo, e, mesmo assim, insiste-se que o problema é de cada aluno em particular, e causas individuais, não raro biológicas, são aventadas, caracterizando o processo de medicalização da educação. Na contramão, é preciso romper com essa lógica e deslocar o olhar para os campos da política, da economia, do coletivo, do institucional, do comum, buscando, assim, construir caminhos para sair da racionalidade neoliberal individualizante que constitui esse olhar.

Trata-se de tarefa complexa, uma vez que, segundo Dardot e Laval (2017, p. 339),

é mais fácil fugir de uma prisão do que sair de uma racionalidade, porque isso significa livrar-se de um sistema de normas instaurado por meio de todo um trabalho de interiorização. Isso vale em particular para a racionalidade neoliberal, na medida em que esta tende a trancar o sujeito na pequena 'jaula de aço' 
que ele próprio construiu para si. Assim, a questão é, primeiro e acima de tudo, como preparar o caminho para essa saída, isto é, como resistir aqui e agora à racionalidade dominante. O único caminho praticável é promover desde já formas de subjetivação alternativas ao modelo da empresa de si.

Se a tarefa é complexa, ela não é impossível. Na trilha dos mesmos autores, a genealogia do neoliberalismo produtora da medicalização revela que essa racionalidade não é o destino único da humanidade; é possível construir outras racionalidades, cabendo a cada um contribuir na produção de outros futuros, o que implica no estabelecimento de relações humanas de cooperação, compartilhamento e comunhão.

Práticas de resistência à medicalização vêm sendo criadas ao longo das últimas décadas no Brasil, protagonizadas por profissionais da educação e da saúde sensíveis às narrativas que constituem a complexidade do processo ensino-aprendizagem. Como referências relevantes, citamos: Orientação à Queixa Escolar (SOUZA, 2007); e Recomendações de práticas não medicalizantes para profissionais e serviços de educação e saúde. (FÓRUM SOBRE MEDICALIZAÇÃO DA EDUCAÇÃO E DA SOCIEDADE, 2013)

Se laudos e diagnósticos povoam o cotidiano escolar, que não sejamos instrumentos obedientes da ordem instituída e questionemos essa realidade. Adorno (1995) se referia a isso ao afirmar que a educação precisa ter como função a emancipação e nunca a conversão das pessoas em seres inofensivos e passivos. Inclusive porque a passividade é uma forma de barbárie, à medida que permite contemplar o horror e se omitir diante dele.

A análise crítica do material construído na pesquisa nos convoca a recuperarmos o caráter político da produção de encaminhamentos, adoecimento e medicalização. Por compreendermos o ser humano como um ser em construção, histórico por excelência, apostamos na constituição de subjetividades que engrossem a resistência ao poder.

Por fim, não podemos desconsiderar que o professor não pode ser culpabilizado pelo fracasso escolar, o que recairia na mesma lógica medicalizante que buscamos questionar. Em outras palavras, o professor não é a causa da epidemia de encaminhamentos que culmina no quarto ano do ensino fundamental, nem da desistência de um olhar mais atento aos alunos a partir do quinto ano. É preciso compreender a política educacional como produtora 
dessa realidade e, com isso, buscar outro caminho fundamentado em compromissos que assumam como prioridades a formação do professor, a valorização profissional em termos de salário e condições de trabalho, um projeto pedagógico da escola construído coletivamente e a autonomia das escolas e do fazer docente. Esses compromissos deveriam ser os "remédios" esperados.

\title{
medicalization of "school failure" in municipal public elementary schools in Vitória, ES, Brazil
}

\begin{abstract}
This study presents an analysis of the process of medicalization of education in municipal primary schools in Vitória, Espírito Santo, Brazil. Its main objective is to know the reasons for referral for medical diagnosis of 1,628 students enrolled in 45 public elementary schools in the school year of 2013. For this purpose, a documentary study was developed adopting quali-quantitative approach. The Statistical Package for the Social Sciences (SPSS), version 20.0, was used for data analysis, using descriptive statistics, with simple frequency tables and cross-linked graphs. Eight categories of analysis that emerged from the referrals were defined, among which, two were highlighted: learning difficulty, making up a total of $67 \%$ of the students referred; and behavioral problem, with 54.8\%. The results also showed that the students referred were mostly males, totaling $67.6 \%$. The predominant age group was between 8 and 10 years, equivalent to $41.3 \%$ of the referred students, followed by the age group between 11 and 13 years, which was $31.6 \%$. This age group corresponds to the first cycle of elementary education, having a percentage equivalent to $72.3 \%$, especially those enrolled in the second and third grades. It was also observed that, from the age of 13 years on, referrals fell abruptly. As for the school year, this drop begins in the fifth year, and the number of referrals in the ninth year is almost non-existent.
\end{abstract}

Keywords: Medicalization. Education. Public School.

\section{La medicalización del "fracaso escolar" en escuelas públicas municipales de educación primaria de Vitória-ES}

RESUMEN: Este estudio presenta un análisis del proceso de medicalización de la educación en escuelas municipales de educación primaria de Vitória, Espírito Santo. Tiene por principal objetivo conocerlos motivos de direccionamiento para diagnóstico médico de 1,628 alumnos matriculados en 45 escuelas públicas de educación primaria, en el año lectivo de 2013. Con ese propósito, fue desarrollado un estudio documental con abordaje cuanti-cualitativo. Fue utilizado para el análisis de los datos el software Statistical Package for the Social Sciences (SPSS), versión 20.0, mediante la estadística descriptiva, con tablas de frecuencia simple y gráficos con cruzamientos. Fueron definidas ocho categorías de análisis que emergieron de los direccionamientos realizados, entre las cuales dos se destacaron: dificultad de aprendizaje, alcanzando un total de $67 \%$ de los alumnos direccionados; y problema de comportamiento, con $54,8 \%$. Los resultados obtenidos demostraron inclusive que los alumnos direccionados eran, en su mayoría, de sexo masculino, totalizando 67,6\%. El grupo etario predominante se encontraba entre 8 y 10 años, equivaliendo 
a $41,3 \%$ de los alumnos direccionados, seguido del grupo etario entre 11 y 13 años, que fue $31,6 \%$. Ese grupo etario corresponde al primer ciclo de la educación primaria, teniendo un porcentaje equivalente a $72,3 \%$, con destaque para los matriculados en el segundo y tercer año. Constatóse, aun, que, desde la edad de 13 años, los direccionamientos caen abruptamente. Cuanto al año escolar, esa caída comienza en el quinto año, siendo casi inexistente el número de direccionamientos realizados en el nono año.

Palabras-1lave: Medicalización. Educación. Escuela Pública.

\section{Referências}

ADORNO, T. W. Educação e emancipação. Rio de Janeiro: Paz e Terra, 1995.

AMERICAN PSYCHIATRIC ASSOCIATION. Manual diagnóstico e estatístico de transtornos mentais, DSM-5. Porto Alegre: Artmed, 2014.

BARROS, D. B. Os usos e sentidos do metilfenidato: experiências entre o tratamento e o aprimoramento da atenção. 2014. 182 f. (Doutorado em Saúde Coletiva) - Universidade do Estado do Rio de Janeiro, Rio de Janeiro, 2014

BASSANI, E. As políticas quantificadoras da educação e as novas formas de exclusão: os inclassificáveis. 2013. 211 f. Tese (Doutorado em Educação) - Programa de Pós-Graduação em Educação, Universidade Federal do Espírito Santo. Vitória, 2013.

IBGE. População. 2010. Disponível em: <www.ibge.gov.br/cidadesat/ topwindow.htm?1 >. Acesso em: 01 out. 2018.

CAPONI, S. Vigiar e medicar: o DSM-5 e os transtornos ubuescos na infância. In: CAPONI, S.; VASQUEZ-VALENCIA, M. F.; VERDI, M. (org.) Vigiar e medicar: estratégias de medicalização da infância. São Paulo: LiberArs, 2016. p. 29-46.

CARVALHO, M. P. O fracasso escolar de meninos e meninas: articulações entre gênero e cor/raça. Cadernos Pagu, Campinas, SP, n. 22, 2004.

CROCHÍK, J. L. Preconceito, indivíduo e cultura. São Paulo: Robe Editora, 1995.

DARDOT, P.; LAVAL, C. A nova razão do mundo: ensaio sobre a sociedade neoliberal. São Paulo: Boitempo, 2016.

FOUCAULT, M. Os anormais. São Paulo: Martins Fontes, 2001.

FÓRUM SOBRE MEDICALIZAÇÃO DA EDUCAÇÃO E DA SOCIEDADE. Carta do IV Seminário Internacional A Educação Medicalizada:

desver o mundo, perturbar os sentidos. 2015a. Disponível em: http://

seminario4.medicalizacao.org.br/carta-do-iv-seminario-internacional-aeducacao-medicalizada-desver-o-mundo-perturbar-os-sentidos/. Acesso em: 26 mar. 2019. 
FÓRUM SOBRE MEDICALIZAÇÃO DA EDUCAÇÃO E DA SOCIEDADE. Nota técnica: o consumo de psicofármacos no Brasil, dados do Sistema Nacional de Gerenciamento de Produtos Controlados ANVISA (20072014). 2015b.

FÓRUM SOBRE MEDICALIZAÇÃO DA EDUCAÇÃO E DA SOCIEDADE. Recomendações de práticas não medicalizantes para profissionais e serviços de educação e saúde. São Paulo, 2013.

ILLICH, I. A expropriação da saúde: nêmesis da medicina. Rio de Janeiro: Nova Fronteira, 1975.

INSTITUTO DE PESQUISA ECONÔMICA APLICADA E FÓRUM BRASILEIRO DE SEGURANÇA PÚBLICA. Atlas da Violência. Rio de Janeiro, 2018.

MOYSÉS, M. A. A. A institucionalização invisivel: crianças-que-nãoaprendem-na-escola. Campinas, SP: Mercado de Letras, 2001.

MOYSÉS, M. A. A. Não às drogas da obediência. Fórum sobre Medicalização da Educação e da Sociedade. 2011. Entrevista concedida a Karina Fusco. Disponível em: http://medicalizacao.org.br/nao-asdrogas-da-obediencia/. Acesso em: 20 set. 2018.

OLIVEIRA, E. C. de; HARAYAMA, R. M.; VIÉGAS, L. de S. Drogas e medicalização na escola: reflexões sobre um debate necessário. Revista Teias, Rio de Janeiro, v. 17, n. 45, p. 99-118, abr./jun. 2016. Disponível em: https://www.e-publicacoes.uerj.br/index.php/revistateias/article/ view/24598/17578. Acesso em: 26 maio 2019.

PATTO, M. H. S. "Escolas cheias, cadeias vazias" nota sobre as raízes ideológicas do pensamento educacional brasileiro. Estudos Avançados, São Paulo, v.21, n.61, 2007.

PATTO, M. H. S. A cidadania negada: políticas públicas e formas de viver. São Paulo: Casa do Psicólogo, 2009.

PATTO, M. H. S. A produção do fracasso escolar: histórias de submissão e rebeldia. São Paulo: Intermeios, 2015.

SOUZA, B. P. (Org.) Orientação à queixa escolar. São Paulo: Casa do Psicólogo, 2007.

SOUZA, B. P.; SOBRAL, K. R. Características da clientela da orientação à queixa escolar: revelações, indicações e perguntas. In: SOUZA, B. P.; SOBRAL, K. R.. (org.) Orientação à queixa escolar. São Paulo: Casa do Psicólogo, 2007. p. 119-134.

SOUZA, M. P. R. Formação de psicólogos para o atendimento a problemas de aprendizagem: desafios e perspectivas. Estilos da Clínica, São Paulo,v. 5,n. 9, 2000.

VITORINO, J. L. Sucesso nas meninas, fracasso nos meninos: o papel dos contextos nos distúrbios de aprendizagem e gênero. Revista Científica Aprender, 3. ed. set. 2009. 
WHITAKER, R. Transformando crianças em pacientes psiquiátricos: fazendo mais mal do que bem. In: CAPONI, S.; VASQUEZ-VALENCIA, M. F.; VERDI, M. (org.) Vigiar e medicar: estratégias de medicalização da infância. São Paulo: LiberArs, 2016. p. 13-28.

WHITAKER, R. Anatomia de uma epidemia: pílulas mágicas, drogas psiquiátricas e o aumento assombroso da doença mental. Rio de Janeiro: Editora Fiocruz, 2017.

Submetido em: 03/12/2018

Aceito em: 17/08/2019 